\title{
Memória, experiência e montagem
}

Rodrigo Amboni

UFSC

\section{Resumo}

Partindo das cartas recebidas por Tarkovski após o lançamento do filme $O$ espelho e algumas ideias lançadas no seu livro Esculpir o tempo, este texto faz uma aproximação dos conceitos benjaminianos de narração, memória e experiência a uma ideia de montagem poética. Tarkovski fala que poesia é a consciência do mundo. No ensaio proponho, a partir de Benjamin, que poesia é a inconsciência do mundo. Uma montagem poética, para conservar sua potência, não deve partir do que já foi processado pela consciência, pois estaria apenas transformando potências em atos fechados. Quando Tarkovski fala em uma lógica poética, em contraponto à lógica "realista" da dramaturgia que se apoia em um enredo pré-determinado, proponho pensar numa falta de lógica. Na falta de lógica da narrativa poética o que se tem é uma operação do pensamento que se aproxima da experiência a partir do inconsciente do mundo. Uma montagem poética opera com impressões da memória e faz essa operação deixando as marcas daquele que monta. As impressões da memória são esquecimentos. São as fissuras provocadas no acontecimento objetivo pela subjetividade do autor. A subjetividade do autor é o esquecimento - que permanece como impressão - do "puro em si" da coisa narrada.

Palavras-chave: Montagem; Memória; Experiência; Walter Benjamin; Andrei Tarkovski.

\section{Resumen}

Partiendo de las cartas recibidas por Tarkovski en el estreno de su película El espejo y de algunas ideas propuestas en su libro Esculpir el tiempo, este texto hace una aproximación de los conceptos benjaminianos de narración, memoria y experiencia a una idea de montaje poético. Tarkovski afirma que la poesía es la conciencia del mundo. En este ensayo propongo, a partir de Benjamin, pensar la poesía como la inconsciencia del mundo. Un montaje poético, para conservar su potencia, no debe partir de lo ya procesado por la conciencia, pues así estaría transformando potencias en actos cerrados. Cuando Tarkovski habla de una lógica poética en oposición a una lógica "realista" de la dramaturgia basada en el enredo, propongo pensar en una falta de lógica cuya operación del pensamiento se acerca a la experiencia a partir del inconsciente del mundo. Un montaje poético opera con las impresiones de la memoria y hace esa operación dejando las marcas del que monta. Las impresiones de la memoria son olvidos, son fisuras provocadas en el acontecimiento objetivo por la subjetividad del autor. La subjetividad del autor es el olvido - que permanece como impresión - del "puro en si" de la cosa narrada.

Palabras clave: Montaje; Memoria; Experiencia, Walter Benjamin, Andrei Tarkovski. 
1. TARKOVSKI, Andrei. Esculpir o tempo, 1998, p. 4. Trecho da nota publicada por um membro do Instituto de Física da Academia de Ciência de Moscou no mural do instituto.

2. Ibidem, p. 2. Carta de uma engenheira civil de Leningrado

3. Ibidem, p. 2. Engenheiro de Sverdlovsk.

4. Ibidem, p. 5.

5. Ibidem, p. 5.
De que fala o filme? De um homem. Não daquele homem em particular, cuja voz ressoa por trás da tela, representado por Innokenti Smoktunovsky. É um filme sobre você, o seu pai, o seu avô, sobre alguém que viverá depois de você, e que, ainda assim, será 'você'. Sobre um homem que vive na terra, que é parte da terra, a qual, por sua vez, é parte dele, sobre o fato de que um homem responde com a vida tanto ao passado quando ao futuro. ${ }^{1}$

$\mathrm{Na}$ introdução de seu Esculpir o tempo, Andrei Tarkovski expõe vários trechos de cartas que foram destinadas a ele a propósito do lançamento de seu filme $O$ espelho. $\mathrm{O}$ debate que propõe Tarkovski ao expor as cartas gira em torno da utilidade e da função de sua obra. Muitas das críticas dos espectadores que escreveram são apenas reclamações, alegações, muitas vezes desaforadas, de que não entenderam o filme. Ao não entender o filme, os questionamentos se voltam para a sua função social e o absurdo que é o estado financiar um filme que, ao não ser entendido, não tem função: "vi seu filme, $O$ espelho. Assisti até o fim, apesar da grande dor de cabeça que me foi provocada na primeira meia hora pelas tentativas de analisá-lo, ou de ao menos compreender alguma coisa do que nele se passava..." "é de admirar que as pessoas responsáveis pela distribuição dos filmes aqui na União Soviética deixem passar tais disparates" Existe nesses posicionamentos uma visão absoluta do mundo, modelada por uma racionalidade que limita a percepção a uma lógica de um discurso progressista e linear. É o sensato impondo-se ao sensível.

Por outro lado, Tarkovski recebe cartas que o motivam e lhe dão uma certa confiança de que seus filmes podem tocar as pessoas a partir de outras formas de pensar e sentir que vão além de uma compreensão sensata e funcional. Uma espectadora de Gorki (atual Nijni Novgorod) escreve: "Obrigado por $O$ espelho. Tive uma infância exatamente assim... Mas você... como pôde saber disso?"'. E segue:

Havia o mesmo vento, e a mesma tempestade... 'Galka, ponha o gato para fora', gritava minha avó... O quarto estava escuro... E a lamparina a querosene também se apagou, e o sentimento da volta de minha mãe enchia-me a alma... E com que beleza você mostra o despertar da consciência de uma criança, dos seus pensamentos!... E, meu Deus, como é verdadeiro... nós de fato não conhecemos o rosto das nossas mães. E como é simples... Você sabe, no escuro daquele cinema, olhando para aquele pedaço de tela iluminado pelo seu talento, senti pela primeira vez na vida que não estava sozinha... ${ }^{5}$

A montagem de imagens e sons de Tarkovski tocou a espectadora de Gorki através de outros sentidos, abrindo fissuras 
na forma tradicional de compreensão de uma narrativa e levando a percepção a entrar nas feridas do discurso sensato. "Havia o mesmo vento, e a mesma tempestade...!”. Essa conexão da espectadora com as imagens se dá a partir do sensível, a partir de uma sensação, de uma impressão da memória que a remete para algum momento esquecido de sua infância, para uma experiência que a faz sentir o vento e a tempestade e não a representação desses através da dramaturgia. É o segundo sentido que Bataille dá para a palavra dramatizar: "é a vontade, que se acrescenta ao discurso, de não se manter no enunciado, de obrigar a sentir o gelado do vento, a estar nu"'.

É daí que vem a dura crítica de Tarkovski ao chamado cinema "realista" ou "naturalista" que, para ele, é um modelo artificial e se distancia da realidade justamente por unir "imagens através de um desenvolvimento linear e rigidamente lógico do enredo" . Para ele, "esta forma exageradamente correta de ligar os acontecimentos geralmente faz com que os mesmos sejam forçados a se ajustar arbitrariamente a uma sequência, obedecendo a uma determinada noção abstrata de ordem". ${ }^{9}$ 'Tarkovski sugere que a montagem pode se dar de uma outra forma, de uma forma em que a sequência dos acontecimentos narrativos ocorra através da lógica do pensamento. Dessa maneira o que se constrói são associações poéticas que intensificam as emoções e tornam o espectador mais ativo ${ }^{10}$.

É por isso que Tarkovski, quando fala de poesia, não pensa nela como um gênero. Para ele a poesia é uma consciência do mundo, uma forma direta e profunda de se relacionar com a realidade ${ }^{11}$. Gostaria de pensar então que para Tarkovski o espectador ativo é aquele que, ao ser tocado por uma montagem do pensamento, faz conexões que se con-fundem com suas memórias e suas experiências, e isso o leva inevitavelmente a montar. Essas conexões não se dão através de um entendimento do discurso e sim a partir de uma espécie de ativação involuntária das impressões da memória provocada por uma montagem que, segundo Tarkovski, se propõe a seguir uma lógica poética do pensamento e não uma ordem rígida imposta pelo enredo. A conexão do e com o espectador acontece por uma montagem - apresentada por imagens e sons - que se constrói a partir de uma "ligação orgânica entre as impressões subjetivas do autor e a sua representação objetiva da realidade" ${ }^{2}$. Não é a toa que Tarkovski diz que o seu mais profundo desejo sempre foi o de conseguir se expressar com absoluta sinceridade sem precisar impor os seus pontos de vista ao espectador; "no entanto, se a visão de mundo transmitida pelo filme puder ser reconhecida por outras pessoas como parte integrante de si próprias, como algo a que nada, até agora, conseguiria dar expressão, que estímulo maior para o meu trabalho eu poderia desejar?”"13. É essa parte integrante de si própria que a espectadora de Gorki sentiu ao ser tocada pelo Espelho de Tarkovski.
6. Ibidem, p. 5.

7. BATAILLE, Georges. $A$ experiência interior: seguida de Método de meditação e Postscriptum. 1953: Suma ateológica, Vol. I, 2016, p. 45.

8. TARKOVSKI, Andrei. Esculpir o tempo, 1998, p. 17.

9. Ibidem, p. 17.

10. É preciso fazer algumas ressalvas às colocações de Tarkovski: como saber de uma suposta lógica do pensamento? E se fosse possível, como não seria artificial?

11. TARKOVSKI, Andrei. Esculpir o tempo, 1998, p. 18.

12. Ibidem, p. 19.

13. Ibidem, p. 8. 
Através das associações poéticas, intensifica-se a emoção e torna-se o espectador mais ativo. Ele passa a participar do processo de descoberta da vida, sem apoiar-se em conclusões já prontas, fornecidas pelo enredo, ou nas inevitáveis indicações oferecidas pelo autor. Ele só tem à sua disposição aquilo que the permite penetrar no significado mais profundo dos complexos fenômenos representados diante dele. Complexidades do pensamento e visões poéticas do mundo não têm de ser introduzidas à força na estrutura do que é manifestamente óbvio. A lógica comum da sequência linear assemelha-se de modo desconfortável à demonstração de um teorema. Para a arte, trata-se de um método incomparavelmente mais pobre do que as possibilidades oferecidas pela ligação associativa, que possibilitam uma avaliação não só da sensibilidade, como também do intelecto. E é um erro que o cinema recorra tão pouco a esta última possibilidade, que tem tanto a oferecer. Ela possui uma força interior que se concentra na imagem e chega ao público na forma de sentimentos, gerando tensão numa resposta diferente a lógica narrativa. ${ }^{14}$

No seu texto sobre $O$ narrador, Benjamin caracteriza dois tipos arcaicos de narradores "que se interpenetram de múlti-

15. BENJAMIN, Walter. Magia e técnica, arte e politica: ensaios sobre literatura e bistória da cultura, 1994, p. 198.

16. Ibidem, p. 199.

17. Ibidem, p. 199. plas maneiras" "15: o camponês sedentário e o marinheiro comerciante. Benjamin diz que "no sistema corporativo associava-se o saber das terras distantes, trazidos para casa pelos migrantes, com o saber do passado, recolhido pelo trabalhador sedentário" ${ }^{16}$. Para ele, essa transmissão de relatos de pessoa a pessoa está relacionada à experiência e também, dentro de sua teoria, à experiência com a memória. Neste mesmo texto Benjamin tenta compreender os motivos do declínio da arte de narrar - e acompanhado a este, o declínio de experiência transmissível. Para ele este declínio se deve principalmente à difusão da informação:

Cada manhã recebemos notícias de todo o mundo. E, no entanto, somos pobres em histórias surpreendentes. A razão é que os fatos já nos chegam acompanhados de explicações. Em outras palavras: quase nada do que acontece está a serviço da narrativa, e quase tudo está a serviço da informação. ${ }^{17}$

Essa oposição entre narração e informação é exemplificada através de um relato de Heródoto sobre o rei do Egito Psamético que, derrotado pelo rei persa Cambises, vira seu prisioneiro. Cambises, com a intenção de humilhar seu prisioneiro, coloca-o para ver o cortejo triunfal dos persas. No cortejo o rei egípcio vê sua filha como serva e seu filho ser conduzido para a execução. Os egípcios que viam esta cena protestavam e lamentavam, enquanto Psamético permanecia indiferente, "mas, quando, 
depois disso, reconheceu um dos seus servos, um velho homem empobrecido, na fileira dos prisioneiros, golpeou a cabeça com os punhos, dando sinais da mais profunda tristeza"18. Essa história, ao não propor uma explicação acerca do motivo pelo qual o rei egípcio perdeu o controle e entristeceu somente após ver o seu servo entre os prisioneiros, possibilita que se encontre as mais variadas explicações, como demonstra Benjamin, e não permite que o relato se esgote. Agora, "se essa história tivesse acontecido hoje (...) sairia em todos os jornais que Psamético amava mais ao criado que aos filhos" ${ }^{\text {19. }}$. O tom irônico e crítico de Benjamin alerta para o quanto a informação simplifica, explica e fecha a história em si mesma, "a informação só tem valor no momento em que é nova. Ela só vive nesse momento, precisa entregar-se inteiramente a ele e sem perda de tempo tem que se explicar nele" ${ }^{20}$, diferente da narração, que conserva indefinidamente o seu poder germinativo justamente por evitar explicações.

A narração, segundo Benjamin, também tem um aspecto particular: ela é uma forma de comunicação artesanal que "não está interessada em transmitir o 'puro em si' da coisa narrada como uma informação ou um relatório. Ela mergulha a coisa na vida do narrador para em seguida retirá-la dele. Assim se imprime na narrativa a marca do narrador, como a mão do oleiro na argila do vaso"21. Benjamin parece afirmar que a narração não seria possível sem esse mergulho do "puro em si" da coisa narrada (o que toca o narrador) no narrador. Mas não apenas isso. Como Benjamin coloca na citação acima, existe nessa relação entre a narração e a coisa narrada, aquela que nos toca e mergulha na vida do narrador, um movimento remissivo que em seguida retira essa coisa do narrador, não sem antes, nesse refluxo, termos as suas marcas, as marcas da sua experiência na coisa que o tocou para depois ser narrada. Em outras palavras, o narrador, ao transmitir a sua experiência, ele também mergulha na coisa que o toca. Essa operação, esse movimento remissivo, mistura o "puro em si" da coisa narrada com as incontáveis e incontroláveis marcas do "sujeito": suas histórias, vivências, experiências, impressões da memória entre tantas outras marcas muitas vezes imperceptíveis. A própria narração de uma experiência se dá também num movimento remissivo entre os sentidos, entre o que está dentro e o que está fora, num constante vai e vem sem começo e nem fim.

“'Ir a la cosa misma' no puede querer decir: 'llegar hasta la constitución de una significación originaria', sino: mantener el paso (no) del pensamiento suspendido sobre este sentido que ya nos ha tocado"22.

A partir de procedimentos técnicos (o cinema, por exemplo), abre-se a possibilidade de outro tipo de experiência (mas, ainda, comum). Não se trata de uma experiência não mediada,
18. Idem. Obras escolhidas vol. 2: Rua de mão única, 1994, p. 276.

19. Ibidem, p. 277.

20. BENJAMIN, Walter. Magia e técnica, arte e politica: ensaios sobre literatura e história da cultura, 1994, p. 204.

21. Ibidem, p. 205.

22. NANCY, Jean-Luc. El sentido del mundo, 2003, p. 25. 
23. NANCY, Jean-Luc. $A$ la escucha, 2015, p. 25. como se fosse possível chegar à experiência de alguma forma prévia ou originária. Sempre estamos mediados (no caso do cinema por instrumentos, aparelhos), e o cinema é passível tanto de abrir quanto de fechar sentidos. As lacunas são justamente os buracos que se abrem e possibilitam novas experiências. Nesse movimento remissivo existirão sempre lacunas que são deixadas justamente por essa relação do "puro em si" da coisa narrada com os sentidos daquele em que a coisa narrada mergulha (e na qual ele mergulha). O narrador opera então por montagem, uma montagem da qual vemos não somente as marcas como também os grandes espaços vazios deixados por essas marcas. Essa é uma das potências da narração, a de privar quem está sendo tocado por ela de explicações, ampliando assim o movimento remissivo para o outro, fazendo-o sentir, vibrar, recomeçar toda a operação novamente. E é justamente naquilo que não está presente que podemos pressentir a presença das mãos do oleiro na argila, pressentir sua presença fantasmática modelando silenciosamente vozes de fantasmas que vagam por uma terra devastada e formam imagens incompletas, interrompidas, como se o narrador nunca alcançasse ouvi-las por completo. Arriscando fazer uma tradução em termos benjaminianos, trata-se da restituição de impressões mnemônicas se transformando em experiências ao se deslocarem em novas circunstâncias: repetição e corte como uma origem.

Trata-se de algo parecido com o acesso a si mesmo de que fala Nancy: "ni a un sí mismo propio (yo), ni al sí mismo de otro, sino a la forma o la estructura del sí mismo como tal, es decir, a la forma, la estructura y el movimiento de una remisión infinita porque remite a aquello (él) que no es nada fuera de la remisión" ${ }^{\prime 23}$.

Para melhor compreender essa relação lembro aqui de Benjamin e sua construção de uma teoria da memória que transita entre Proust e Freud. Para Benjamin, a memória está intimamente ligada ao inconsciente e à experiência (Erfahrung), enquanto a lembrança está ligada ao consciente e à vivência (Erlebnis). A Erfahrung aproxima-se ao que seria uma experiência bruta, aquela em que não há uma intervenção da consciência e em que os acontecimentos não se fixam com exatidão na lembrança, mas que agem a partir do inconsciente sob a forma de dados acumulados que afluem à memória pela ação de certos estímulos (como a mediação através da técnica). A Erlebniss, entretanto, designa aqueles acontecimentos em cujo desenvolvimento há uma intervenção da consciência e em que o caráter de fatos faz com que essa mesma consciência os pretenda fixáveis em algum lugar. Para desdobrar sua teoria, Benjamin faz uma citação de Reik: "a função da memória consiste em proteger as impressões; a lembrança tende a desagregá-las. A memória 
é essencialmente conservadora; a lembrança é destrutiva" 24 . Benjamin escreve, a partir da leitura de Freud, que o consciente surge no lugar de uma impressão mnemônica, apagando essas impressões. As impressões mnemônicas são mais intensas e duradouras se elas acontecem sem passar por um processo de conscientização. É então que Benjamin traduz esse conceito freudiano aos termos de Proust: "só pode se tornar componente da memória involuntária aquilo que não foi expressa e conscientemente vivenciado, aquilo que não sucedeu ao sujeito como vivência" ${ }^{25}$. Proust, em sua busca do tempo perdido, não estaria à procura do efetivamente vivido e sim da rememoração: "pois o importante, para o autor que rememora, não é o que ele viveu, mas o tecido de sua rememoração"26, já que o "acontecimento vivido é finito, ou ao menos encerrado na esfera do vivido, ao passo que o acontecimento lembrado é sem limites, porque é apenas uma chave para tudo o que veio antes e depois" ${ }^{27}$.

Ainda a partir da leitura de Freud, Benjamin diz que o consciente não registra nenhum traço da memória e que na verdade age como proteção contra esses estímulos, chamados por Benjamin de choques: "o fato de o choque ser assim amortecido e aparado pelo consciente emprestaria ao evento que o provoca o caráter de experiência vivida em sentido restrito. E, incorporando imediatamente este evento ao acervo das lembranças conscientes, o tornaria estéril para a experiência poética" 28 . A lembrança conscientiza as impressões da memória e as transforma em vivência, fechando suas possibilidades, retirando sua potência e destruindo essas impressões. Já a memória guarda as impressões do passado sem permitir seu acabamento, conservando essa fissura - essa abertura - do passado.

Acredito importante lembrar que é a partir desses conceitos de Erfahrung e Erlebniss, memória e lembrança, consciente e inconsciente, que Benjamin desenvolve o conceito de distração. Por uma questão de defesa ao choque, processamos os acontecimentos conscientemente e não sobra quase nada para as impressões da memória. A distração seria algo como ignorar o choque e encher-se dessas impressões, que são ricas para a experiência poética. Para Benjamin esta é a subversão do cinema: a distração quebra a força anestesiante do choque.

Tarkovski fala que poesia é uma consciência do mundo ${ }^{29}$. Gostaria de propor agora, a partir de Benjamin, que poesia é a inconsciência do mundo. E uma montagem poética, para conservar - assim como a memória conserva - sua potência, não deve partir do que já foi processado pela consciência, pois es-
24. Theodor Reik. Der überrascbte Psychologe. Über Erraten und Verstehen unbewusster Vorgänge, apud. BENJAMIN, Walter. Charles Bandelaire um lírico no ange do capitalismo, 1989 , p. 108.

25. BENJAMIN, Walter. Charles Baudelaire um lírico no auge do capitalismo, 1989, p. 108.

26. Idem. Magia e técnica, arte e política: ensaios sobre literatura e bistória da cultura, 1994, p.37.

27. Ibidem, p. 37.

28. Idem. Charles Baudelaire um lírico no ange do capitalismo, 1989, p. 110.

29. TARKOVSKI, Andrei.

Esculpir o tempo, 1998, p. 17-18. 
taria apenas transformando potências em um ato fechado em si mesmo. Quando Tarkovski fala em uma lógica poética, em contraponto a uma lógica que se diz realista e tradicional da dramaturgia que se guia através de um enredo pré-determinado, gostaria de pensar, mesmo ainda sendo uma lógica, numa falta de lógica. Na falta de lógica de uma narrativa poética o que se tem é uma operação do pensamento que se aproxima de uma experiência a partir do inconsciente do mundo. Uma montagem poética é aquela que opera com as impressões da memória e faz essa operação deixando as digitais daquele que monta, como as marcas das mãos do oleiro no vaso. As impressões da memória são esquecimentos. São todas as fissuras provocadas no acontecimento objetivo pela subjetividade do autor. A subjetividade do autor é um esquecimento - que permanece como impressão - do "puro em si" da coisa narrada. E somente assim o autor narra sem informar.

Gostaria de pensar então que aquela narrativa linear, que Tarkovski chama de dramaturgia tradicional, da qual ele critica a forma como impõe seu caráter "realista" e "naturalista", é uma instrumentalização da montagem que apaga sua potência na explicação, na linearidade, na sua sensatez. Em termos benjaminianos, é uma montagem informativa, que se fecha em si mesma e não dá nada mais ao espectador além da satisfação de ter entendido, de ter captado um determinado discurso fechado em sua lógica funcional. O que ocorre nessa relação é um processo de conscientização, não do mundo, como na poética de Tarkovski, mas do espectador e do próprio autor, no qual a montagem, estéril para a experiência poética, não passa de um ato incapaz de ativar as impressões mnemônicas (ou talvez até mesmo gerar essas impressões) e que tem como função a afirmação de um modelo narrativo - e, por que não, de mundo - no qual os choques são aparados pelo consciente, impedindo assim outros tipos de reflexões que sejam capazes de se desviar, ou ainda, ir além desse modelo (aproximando-se assim do espaço dos sonhos).

Faço uma correlação desse modelo de montagem com o que Proust chama de memória voluntária. A memória voluntária é uma lembrança determinada pela ação do intelecto e que não guarda nenhum traço da experiência, nenhuma marca das mãos do oleiro. Já na falta de lógica de uma montagem poética estamos entregues ao acaso. Aqui penso no acaso como o que sugere Proust, já que a montagem poética se dá por impressões

30. Marcel Proust. A la recherché du temps perdu, tome I: Du coté de chez Swann, apud. BENJAMIN, Walter. Charles Baudelaire um lírico no ange do capitalismo, 1989, p. 106. da memória, e essas impressões são ativadas pela memória involuntária, uma vez que o passado, para Proust, se encontra "em um objeto material qualquer, fora do âmbito da inteligência e de seu campo de ação. E é questão de sorte, se nos deparamos com ele antes de morrermos ou se jamais o encontramos"30. Então a 
montagem poética se dá pelo acaso, por conexões impensadas, no momento em que recebemos de um objeto material qualquer o inesperado e ainda não tivemos tempo para organizá-lo, processá-lo conscientemente. Não foi a partir do acaso de ir assistir a um filme no cinema e ser surpreendida com o toque da montagem de imagens e sons de Tarkovski que a espectadora de Gorki teve suas impressões da memória ativadas involuntariamente? "Mas você... como pôde saber disso?"31. É evidente que Tarkovski não sabia, não tinha conhecimento das memórias de infância da espectadora de Gorki, mas a partir da falta de lógica de sua montagem poética ele "é capaz de ir além dos limites da lógica linear, para poder exprimir a verdade e a complexidade profundas das ligações imponderáveis e dos fenômenos ocultos da vida"32 (e se não exprimir, pelo menos indicar, abrir o jogo para).

\section{Referências}

BATAILLE, Georges. A experiência interior: seguida de Método de meditação e Postscriptum. 1953: Suma ateológica, Vol. I. Tradução de Fernando Scheibe. Belo Horizonte: Autêntica, 2016.

BENJAMIN, Walter. Charles Baudelaire um lírico no ange do capitalismo. Tradução José Martins Barbosa, Hemerson Alves Baptista. São Paulo: Brasiliense, 1989.

Magia e técnica, arte e politica: ensaios sobre literatura e história da cultura. Tradução de Sérgio Rouanet. São Paulo: Brasiliense, 1994.

- Obras escolbidas vol. 2: Rua de mão única. Tradução Rubens Rodriguez Torres Filho e José Carlos Martins Barbosa. São Paulo: Brasiliense, 1995.

NANCY, Jean-Luc. A la escucha. Tradução Horacio Pons.

Buenos Aires: Amorrortu, 2015.

. El sentido del mundo. Tradução Jorge Manuel Casas.

Buenos Aires: La marca editora. 2003.

O ESPELHO. Direção: Andrei Tarkovski. União Soviética, 1975. Cor, PB, 105 min.

TARKOVSKI, Andrei. Esculpir o tempo. Tradução de Jefferson Luiz Camargo. São Paulo: Martin Fontes, 1998.
31. TARKOVSKI, Andrei.

Esculpir o tempo, 1998, p. 5.

32. Ibidem, p. 19.

Submissão: $10 / 05 / 2017$

Aceite: 20/07/2017 